\title{
Respiratory symptoms in relation to indoor exposure to mite and cat allergens and endotoxins
}

\author{
U. Gehring*,\#, J. Heinrich*, B. Jacob*, K. Richter ${ }^{\Uparrow}$, B. Fahlbusch ${ }^{+}$, G. Schlenvoigt ${ }^{+}$, W. Bischof $^{\S}$, \\ $\mathrm{H}-\mathrm{E}$. Wichmann*,\#, for the Indoor Factors and Genetics in Asthma (INGA) Study group
}

Respiratory symptoms in relation to indoor exposure to mite and cat allergens and endotoxins. U. Gehring, J. Heinrich, B. Jacob, K. Richter, B. Fahlbusch, G. Schlenvoigt, $W$. Bischof, H-E. Wichmann, for the Indoor Factors and Genetics in Asthma (INGA) Study group. (C) ERS Journals Ltd 2001.

ABSTRACT: The authors investigated the relationship between respiratory symptoms in adults and exposure to mite and cat allergens, the role of endotoxins in house dust, the effects of mixtures of several allergens, and interactions between allergen exposure and allergic sensitization.

Within a nested case-control study, 405 subjects aged $25-50$ yrs from two German cities answered a standardized questionnaire. Allergen-specific immunoglobulin-E was measured. Dust samples were taken from the subjects' homes to determine exposure to mite (Dermatophagoides pteronyssinus antigen 1 Der $p 1)$ and (D. farinae antigen 1 Der $f$ 1) and cat (cat antigen d1 Fel $d$ 1) allergen and endotoxin content in settled house dust.

Exposure to Der $f 1$ and Der $p 1$ plus $\operatorname{Der} f 1>10 \mu \mathrm{g} \cdot \mathrm{g}^{-1}$ of mattress dust, respectively, increased the risk of wheeze and breathlessness (odds ratios (OR): 4.04, 95\% confidence interval (CI): 1.53-10.64, OR: 2.78, 95\% CI: 1.06-7.28). Fel $d$ d $>8 \mu \mathrm{g} \cdot \mathrm{g}^{-1}$ was positively associated with cough at night (OR: $2.74,95 \%$ CI: $1.22-6.17$ ), noteworthy also in the nonsensitized subjects. Subjects exposed to elevated concentrations of more than one allergen had an up to seven-fold increase in the risk of respiratory symptoms, compared to nonexposed subjects. Sensitized subjects exposed to elevated concentrations of $\mathrm{Der} f 1$ or $\mathrm{Fel} d 1$ were found to have the highest risk of asthma attacks and respiratory symptoms. No statistically significant association was found between exposure to endotoxins and respiratory health.

Indoor exposure to Dermatophagoides farinae antigen 1 and cat antigen $\mathrm{d} 1$ is a risk factor for respiratory symptoms in adults, and for cat antigen $\mathrm{d} 1$ even in nonsensitized subjects. The risk is increased if subjects are exposed to a mixture of allergens or if they are sensitized in addition to high exposure.

Eur Respir J 2001; 18: 555-563.
*GSF - National Research Centre for Environment and Health, Institute of Epidemiology, Neuherberg, Germany. ${ }^{\#}$ Chair of Epidemiology, Institute of Medical Data Management, Biometrics and Epidemiology, LudwigMaximilians-University of Munich, Munich, Germany. "Centre for Pneumology and Thoracic Surgery, Pulmonary Research Institute at Grosshansdorf Hospital, Grosshansdorf, Germany. ${ }^{+}$Institute of Clinical Immunology, FriedrichSchiller-University of Jena, Jena, Germany. Institute of Occupational, Social and Environmental Medicine, Friedrich-Schiller-University of Jena, Erfurt, Germany.

Correspondence: U. Gehring, GSF National Research Centre for Environment and Health, Institute of Epidemiology, Geb 56, Ingolstädter Landstrasse 1, 85764 Neuherberg, Germany.

Fax: 498931873380

Keywords: Allergens

cat

endotoxins

house dust

mite

respiratory symptoms

Received: November 152000

Accepted after revision March 302001

This study was supported by the Federal Ministry for Education, Science, Research, and Technology, Grant No. 01 EE 93016.
The prevalence of asthma and immunoglobulin-E (IgE)-mediated atopic diseases increased in many Western countries over recent decades [1]. Inhalant allergens play a major role in the pathogenesis of allergic asthma and allergic rhinitis. Indoor allergens from house dust mites, cat dander, cockroaches, and fungi are of particular importance. The house dust mites Dermatophagoides pteronyssinus and D. farinae are the predominant sources of inhalant allergens in most parts of the world [2].

Which individual indoor allergen plays the major role, is a question of area-specific exposure to a single allergen or a mixture of several allergens. As mites cannot survive in very dry climatic conditions, exposure to mites does not play a major role in the development of allergic sensitization in dry climates [3]. Cockroaches may be the predominant allergen exposure in USA inner cities [4, 5], but not in Germany [6].

There is increasing evidence for the impact of allergen exposure early in life on the development of allergic sensitization [7-9], but exposure to allergens later in life might be, at least in sensitized subjects, associated with the development of persistent inflammation in the airway wall, and consequently, with respiratory symptoms.

The aim of this paper was to study the relationship between asthma attacks and respiratory symptoms in 
adults and exposure to mite and cat allergen content in settled house dust. As allergen exposure constitutes only one element of the indoor environment, and differences in allergen levels could reflect overall differences in the indoor environment, the role of endotoxins was also studied. Furthermore, the effect of mixtures of several indoor allergens and interactions between indoor allergen exposure and allergic sensitization was analysed.

\section{Materials and methods}

\section{Study design}

To enrich the population-based sample with atopic subjects, this study on indoor factors and genetics in asthma (INGA) was designed as a nested case-control study following a cross-sectional study performed from 1990-1992 in the two German cities of Erfurt and Hamburg within the European Community Respiratory Health Survey (ECRHS) [10-12]. The methods of the ECRHS are described in detail elsewhere [12]. On the basis of the study results of the ECRHS in 1990-1992, cases and controls were defined. Every subject willing to participate attended the centre again for a detailed questionnaire, including respiratory symptoms and determination of specific IgE. The study was performed from June 1995 November 1996 and an identical methodology was followed in the two centres. The study protocol had been approved by the local ethics committees and all subjects gave their informed written consent.

\section{Study population}

The study population consisted of a subset of the subjects who had participated within the ECRHS in Erfurt and Hamburg. Cases for the present study were defined as subjects fulfilling at least one of the following four conditions according to the results from the ECRHS (1990-1992): 1) asthma diagnosed by a physician according to the long questionnaire of the ECRHS [12]; 2) at least one positive specific serum IgE $\left(>0.35 \mathrm{kU} \cdot \mathrm{L}^{-1}, \mathrm{CAP}\right.$ system, Pharmacia and Upjohn, Stockholm, Sweden) against grass, birch, cat dander, D. pteronyssinus or Cladosporium herbarum; 3) at least one positive skin-prick test reaction (mean wheal diameter $\geqslant 3 \mathrm{~mm}$ ) against the allergens mentioned above; and 4) provocative dose causing a $20 \%$ fall in forced expiratory volume in one second (FEV1) (PD20) $\leqslant 2.0 \mathrm{mg}$ methacholine or positive bronchodilator test. The subjects of the control group did not show any of these conditions at the ECRHS.

Based on these criteria, 107 cases and 106 controls were recruited from a random list of 538 cases and 621 controls in Hamburg, and 115 cases and 109 controls out of 363 cases and 368 controls in Erfurt. Fourhundred and five of these subjects (204 in Erfurt and 201 in Hamburg, 205 cases and 200 controls) agreed to measurements of indoor exposure to mite (D. pteronyssinus antigen 1, Der $p 1$, and D. farinae antigen $1, \operatorname{Der} f 1$ ) and cat (cat antigen d1 Fel $d$ 1) allergens and endotoxins in their apartments.

\section{Questionnaire}

The questionnaire used in the INGA study to asses a history of asthma attacks and respiratory symptoms within the past 12 months, smoking, and social status had been developed according to the validated long questionnaire with 71 items used in the ECRHS [12]. The validated German version of the original ECRHS questionnaire was shortened to 40 items without changing the questions or their wording.

\section{Allergic sensitization}

Allergic sensitization in the INGA study was assessed by measurement of specific $\operatorname{IgE}$ against Alternaria alternata (m6), Aspergillus fumigatus (m3), tree pollen (tx5), birch (t3), C. herbarum (m2), D. pteronyssinus (d1), D. farinae (d2), grass pollen (gx1, gx4), Phleum pratense (g6), weed pollen (wx3), Blatella germanica (i6), dog (e5), and cat dander (e1) using the IgE CAP system. Allergic sensitization was defined as at least one of the specific $\operatorname{IgE}$ listed above $>0.70 \mathrm{kU} \cdot \mathrm{L}^{-1}$. This differs from the definition used for definition of cases, but the cut-off point of $0.70 \mathrm{kU} \cdot \mathrm{L}^{-1}$ seemed to be more reliable.

\section{Lung function}

Spirometric measurements were performed using pneumotachograph-based electronic spirometers. For details, see RICHTER et al. [13].

\section{Measurement of allergen and endotoxin content of house dust}

The homes were visited from June 1995-November 1996 by trained personnel. In each apartment, dust samples were taken from the living room floor, from the bedroom floor, and from the mattress surface according to a standardized protocol [14]. All dust samples were taken using the same type of vacuum cleaner (Flüsterjet Vitall 371, Philips, Hamburg, Germany) by vacuuming an area of $1 \mathrm{~m}^{2}$ for $2 \mathrm{~min}$ at any of the three locations. Dust was collected on cellulose filters using sampling nozzles and filter boxes (ALK Laboratories, Hørsholm, Denmark). Samples were stored in filter boxes at $-20^{\circ} \mathrm{C}$ until extraction. Dust samples were not sieved before extraction.

Sample allergen content was measured by means of a monoclonal enzyme-linked immunosorbent assay (ELISA) [6] with standards UVA 93/03, UVA 93/02, and UVA 94/01 (Indoor Biotechnologies, Clwyd, UK). Allergen concentrations are expressed as $\mathrm{ng} \cdot \mathrm{gram}^{-1}$ of dust. The lower limit of detection was $10 \mathrm{ng} \cdot \mathrm{g} \mathrm{dust}^{-1}$ for Der $p 1$ and $\operatorname{Der} f 1$, and $15 \mathrm{ng} \cdot \mathrm{g}$ dust $^{-1}$ for Fel $d 1$. Endotoxin content in living room floor dust was quantified using a chromogenic kinetic Limulus amoebocyte lysate test described in [15]. Escherichia coli endotoxin (lot no. 5L570, Bio Whittaker, Walkersville, UK) was used as the standard endotoxin. The potency of this standard was 14.5 endotoxin unit $(\mathrm{EU}) \cdot \mathrm{g}^{-1}$. Endotoxin concentrations are expressed as $\mathrm{ng} \cdot \mathrm{gram}^{-1}$ of dust. 


\section{Definition of exposure}

Exposure to allergens is considered of major importance while sleeping, since people come into closest contact with mites in their beds. Therefore, the analysis of the relationship between allergens in house dust and respiratory symptoms was restricted to allergen concentrations in mattress dust.

Allergen levels were classified into low and high, defining subjects exposed to $>10 \mu$ g group I dust mite allergen per gram of dust or $>8 \mu \mathrm{g}$ cat allergen per gram of dust as highly exposed, which are the threshold levels supposed to increase the risk of sensitization and asthmatic symptoms [16, 17]. Exposure to endotoxins was categorized into three categories defining exposure to $<1,100 \mathrm{ng} \cdot \mathrm{g}$ dust $^{-1}$ as low, $1,100-4,700 \mathrm{ng} \cdot \mathrm{g}$ dust $^{-1}$ (25th-75th percentile) as medium and $>4700 \mathrm{ng} \cdot \mathrm{g} \mathrm{dust}^{-1}$ as high.

\section{Statistical methods}

Because of the lognormal distribution of the allergen and endotoxin levels, geometric means (GM) and 95\% confidence intervals (CI) are presented to characterize distributions. Concentrations less than the detection limit were assigned a value of one-half of the detection limit. Correlations between allergens and endotoxins were expressed as Spearman correlation coefficients.

The definition of "case" in the present study was found to be inadequate as it was not a well-defined clinical entity. Consequently outcomes other than case/control were to be analysed (i.e. case/control data was not analysed as designed, but as cross-sectional data). In order to do this, it was necessary to show that a relationship between exposure and the respective outcome was not just a consequence of the selection process. This was approached by adjusting for "caseness".

Associations between allergen concentrations in mattress dust, endotoxin concentrations in living room floor dust and the potentially confounding factors of region, season of dust sampling, age, education, and active smoking were analysed by means of the Wilcoxon two-sample test and the Kruskal-Wallis test, respectively. For the age variable, tertiles were used as cut-off points.

Multiple logistic regression analysis was used to estimate the effects of mite and cat allergens in mattress dust and endotoxins in living room floor dust on the outcomes listed above. Adjusted odds ratios (OR) with 95\% CI are presented. Statistical significance was set at a conventional $5 \%$ level, and marginal significance at a $10 \%$ level.

\section{Results}

\section{Description of the study population}

A description of the studied sample of subjects is given in table 1 . Concerning respiratory symptoms, highest prevalence was observed for wheeze.
Table 1.-Demographic characteristics of study participants, prevalence of asthma attacks, self-reported respiratory symptoms, allergic sensitization, and baseline lung function

$\begin{array}{cc}\text { Prevalence } & \text { Frequency } \\ \% & \mathrm{n} / \mathrm{N}\end{array}$

\begin{tabular}{|c|c|c|}
\hline \multicolumn{3}{|l|}{ Demographic characteristics } \\
\hline \multicolumn{3}{|l|}{ Place of residence } \\
\hline Erfurt & 50.4 & $204 / 405$ \\
\hline Hamburg & 49.6 & $201 / 405$ \\
\hline Sex F & 47.2 & $191 / 405$ \\
\hline Age yrs* & $38.5 \pm 6.7$ & \\
\hline \multicolumn{3}{|l|}{ Education } \\
\hline$\leqslant 8$ grades & 17.8 & $72 / 405$ \\
\hline 10 grades & 41.5 & $168 / 405$ \\
\hline$\geqslant 12$ grades & 40.7 & $165 / 405$ \\
\hline Active smokers & 38.5 & $156 / 405$ \\
\hline \multicolumn{3}{|l|}{ Parameters of respiratory health } \\
\hline Asthma attacks & 2.7 & $11 / 405$ \\
\hline Wheeze & 13.1 & $53 / 405$ \\
\hline Wheeze and breathlessness ${ }^{\#}$ & 5.2 & $21 / 404$ \\
\hline Wheeze w/o cold ${ }^{\#}$ & 7.9 & $32 / 403$ \\
\hline Shortness of breath at rest ${ }^{\#}$ & 5.4 & $22 / 405$ \\
\hline Breathlessness at night & 4.9 & $20 / 405$ \\
\hline Cough at night ${ }^{\#}$ & 8.6 & $35 / 405$ \\
\hline $\begin{array}{l}\text { Cough w/o cold in winter } \\
>3 \text { months (habitually) }\end{array}$ & 4.4 & $18 / 405$ \\
\hline Allergic sensitization & 31.8 & $126 / 396$ \\
\hline Sensitization to mite & 9.8 & $39 / 396$ \\
\hline Der $p^{+}$ & 9.6 & $38 / 396$ \\
\hline $\operatorname{Der} f^{+}$ & 7.8 & $31 / 396$ \\
\hline Sensitization to cat dander ${ }^{+}$ & 8.1 & $32 / 396$ \\
\hline Current asthma medication & 2.0 & $8 / 505$ \\
\hline \multicolumn{3}{|l|}{ Baseline lung function $n=394$} \\
\hline FEV1 L* & $3.85 \pm 0.85$ & \\
\hline FVC L* & $4.60 \pm 1.02$ & \\
\hline
\end{tabular}

$\mathrm{n} / \mathrm{N}$ : number of subjects/total number of subjects; F: female; Der p: Dermatophagoides pteronyssinus; Der f: D. farinae; FEV1: forced expiratory volume in one second; FVC: forced vital capacity; w/o: without. ${ }^{*}$ : data are presented as mean \pm SD; \#: past 12 months; $\overbrace{}^{\text {: }}$ at least one serum-specific immonoglobulin-E (IgE) $\geqslant 0.70 \mathrm{kU} \cdot \mathrm{L}^{-1}$ against Alternaria alternata (m6), Aspergillus fumigatus (m3), tree pollen (tx5), birch (t3), Cladosporium herbarum (m2), D. pteronyssinus (d1), D. farinae (d2), grass pollen (gx1, gx4), Phleum pratense (g6), dog dander (e5), cat dander (e1), weed pollen (wx3), and Blatella germanica $(\mathrm{i6}){ }^{+}{ }^{+}$: serum-specific $\mathrm{IgE} \geqslant 0.70 \mathrm{kU} \cdot \mathrm{L}^{-1}$.

Prevalence of the remaining respiratory symptoms was $<10 \%$. Allergic sensitization (based on the specific IgE measurements conducted in the INGA study) to at least one of the allergens was found in $31.8 \%$ of the subjects. Sensitization to mites occurred more frequently than sensitization to cat.

\section{Allergen and endotoxin concentrations in house dust}

Table 2 presents the distributions of allergen and endotoxin levels for the different sampling locations. Highest concentrations of mite allergens were found in mattress dust and lowest concentrations in living room floor dust, whereas $\mathrm{Fel} d 1$ concentrations were highest in living room floor dust and lowest in mattress dust. Levels of $\operatorname{Der} f 1$ were generally higher than 
Table 2.-Allergen and endotoxins concentrations in house dust samples from three different sampling locations expressed as ng per gram of dust

\begin{tabular}{lccc}
\hline & & Sampling location \\
\cline { 2 - 4 } & Mattress & Bedroom floor* & Living room floor $^{\#}$ \\
\hline Total subjects $n$ & 405 & 365 & 405 \\
Der $p$ & $169(125-228)$ & $55(41-75)$ & $26(21-33)$ \\
Der $f 1$ & $421(305-581)$ & $188(141-252)$ & $83(64-108)$ \\
Der $p$ 1+Der $f 1$ & $1403(1041-1890)$ & $212(165-273)$ & $523(392-700)$ \\
Fel 1 1 & $424(313-573)$ & $469(342-644)$ & $575(425-776)$ \\
Endotoxin & NM & NM & $2274(2030-2547)$ \\
\hline
\end{tabular}

Data are presented as geometric means (GM) with $95 \%$ confidence intervals $(\mathrm{CI})$ in parentheses unless otherwise stated. Der $p$ : Dermatophagoides pteronyssinus antigen 1; Der $f$ 1: D. farinae antigen 1; Fel d 1: cat antigen d 1; NM: not measured. *: there were no separate bedrooms in 40 homes; \#: rooms used as both bedroom and living room were defined as living rooms. Concentrations less than the detection limit were estimated by one-half of the detection limit.

levels of $\operatorname{Der} p$ 1. Weak, but statistically significant $(p<0.05)$ correlations were found between Der $p 1$ and $\operatorname{Der} f 1(\mathrm{r}=0.35)$, Der $p 1$ and Fel $d 1(\mathrm{r}=0.12), \operatorname{Der} f 1$ and Fel $d 1(\mathrm{r}=0.15)$ and endotoxins and $\operatorname{Der} p 1$ $(\mathrm{r}=0.20), \operatorname{Der} f 1(\mathrm{r}=0.15)$, and Fel $d 1(\mathrm{r}=0.21)$.

\section{Allergen and endotoxin levels and potentially con- founding factors}

Concentrations of all indoor factors were significantly higher in Hamburg compared to Erfurt (Der p 1: GM 344 versus $84 \mathrm{ng} \cdot \mathrm{g}^{-1}$, Der $f$ 1: 1,114 versus $161 \mathrm{ng} \cdot \mathrm{g}^{-1}$; Der $p 1$ plus Der $f$ 1: 3,621 versus $551 \mathrm{ng} \cdot \mathrm{g}^{-1}$; Fel d 1: 854 versus $213 \mathrm{ng} \cdot \mathrm{g}^{-1}$; endotoxin: 2,713 versus $\left.1,911 \mathrm{ng} \cdot \mathrm{g}^{-1} ; \mathrm{p}<0.01\right)$. There was a tendency towards higher $\operatorname{Der} f 1$, Der $p 1$ plus $\operatorname{Der} f$ 1 , and endotoxin levels in homes of subjects with the lowest educational level ( $\mathrm{p}<0.10$, data not shown).

\section{Multiple logistic regression analysis}

Results of multiple logistic regression analyses are shown in table 3 . Statistically significant associations $(\mathrm{p}<0.05)$ were found between Der $f 1$ and the sum of $\operatorname{Der} p 1$ and $\operatorname{Der} f 1$ in mattress dust and wheeze and breathlessness, whereas a level of $>8 \mu \mathrm{g} \mathrm{Fel} d 1$ per gram of dust increased the risk of cough at night. No statistically significant association was found between endotoxin levels in living room floor dust and asthma attacks and respiratory symptoms; however, the risk tended to be higher in highly exposed subjects.

Distinguishing between exposure to single allergens and mixtures of several allergens, the risk of respiratory symptoms (except wheeze) was found to be highest among subjects exposed to elevated concentrations of at least two allergens (Der $p$ and/or Der $f 1$ and/or $\mathrm{Fel} d \mathrm{1}$ ). The respective ORs and 95\% CIs are presented in figure 1 where estimable. Subjects exposed to elevated concentrations of at least two of the regarded allergens had a six- to seven-fold increase in the risk of wheeze and breathlessness and cough without cold in winter compared to nonexposed subjects. Because of sample size limitations, it was not possible to differentiate between different types of allergen mixtures.
Prevalence of asthma attacks and respiratory symptoms related to allergic sensitization are shown in figure 2. Sensitized subjects were found to have an increased risk of asthma attacks and respiratory symptoms compared to nonsensitized subjects. Interactions between allergic sensitization and exposure to elevated concentrations of Der $f 1$ and Fel $d 1$ are presented in table 4 . Because of sample size limitations, it was not possible to classify sensitization into sensitization to related (Der $p 1 / \operatorname{Der} f 1$ or Fel $d 1$ ) and nonrelated allergens. Sensitized subjects exposed to elevated concentrations of $\mathrm{Der} f 1$ or $\mathrm{Fel} d 1$ were found to have the highest risk of asthma attacks and respiratory symptoms. In addition, sensitized subjects exposed to $\leqslant 10 \mu \mathrm{g} \operatorname{Der} f 1$ per gram of dust were found to have a five-times higher risk of wheeze and breathlessness $(p<0.05)$, compared to nonsensitized subjects exposed to $\leqslant 10 \mu \mathrm{g} \operatorname{Der} f 1$ per gram of dust.

Nonsensitized subjects exposed to $>10 \mu \mathrm{g} \operatorname{Der} f 1$ per gram of dust were not found to have an increased risk of asthma attacks or respiratory symptoms compared to nonsensitized subjects exposed to $\leqslant 10 \mu \mathrm{g} \operatorname{Der} f 1$, but if subjects were sensitized in addition to high exposure, they were found to have an increased risk of asthma attacks $(\mathrm{p}<0.05)$, and wheeze and breathlessness $(\mathrm{p}<0.05)$. Sensitized subjects exposed to $\leqslant 8 \mu \mathrm{g} \mathrm{Fel} d 1$ per gram of dust showed a statistically significant increase in the risk of wheeze and breathlessness and breathlessness at night compared to nonsensitized subjects exposed to $\leqslant 8 \mu \mathrm{g} \mathrm{Fel} d$ 1 per gram of dust. Nonsensitized subjects exposed to elevated concentrations of $\mathrm{Fel} d 1 \mathrm{had}$ a significantly higher risk of breathlessness at night, and cough at night $(\mathrm{p}<0.05)$ compared to nonsensitized subjects exposed to low concentrations of $\mathrm{Fel} d 1$. The risk of wheeze, wheeze and breathlessness, and shortness of breath at rest was strongly increased if subjects were exposed to $>8 \mu \mathrm{g} \mathrm{Fel} d 1$ per gram of dust in addition to sensitization.

\section{Discussion}

The aim of this study was to assess: first, whether a relationship existed between indoor exposure to mite and cat allergens and endotoxins and asthma attacks 


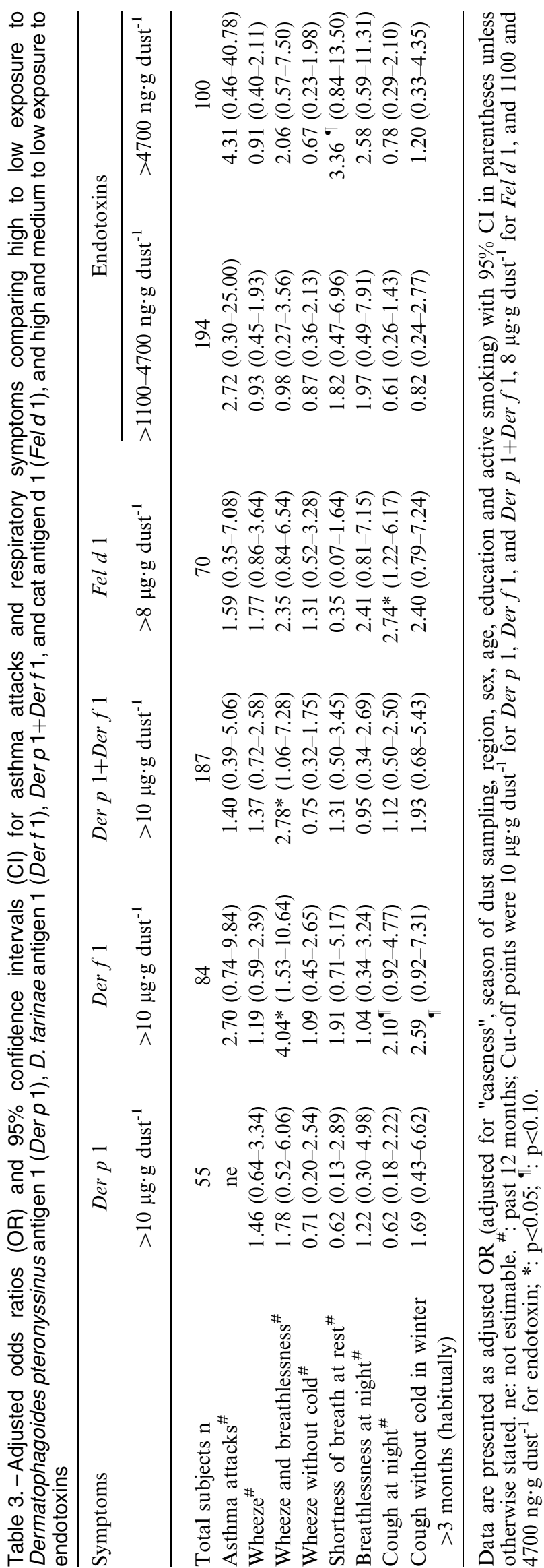

and respiratory symptoms in adults; second, the effect of mixtures of several allergens; and third, whether there was an interaction between allergen exposure and allergic sensitization.

Some of the respiratory symptoms were found to be associated with exposure to high levels of Der $f 1$ and Fel $d$ 1, but not with Der $p$ 1. Subjects exposed to elevated levels of more than one allergen, were found to have up to a seven-fold risk of respiratory symptoms. Sensitized subjects exposed to elevated levels of Der $f 1$ or Fel $d 1$ had an increased risk of asthma attacks and respiratory symptoms, compared to sensitized subjects exposed to low levels of $\operatorname{Der} f 1$ and $\mathrm{Fel} d \mathrm{l}$ and nonsensitized subjects exposed to elevated levels of $\operatorname{Der} f 1$ or $\mathrm{Fel} d$, respectively.

\section{Allergen and endotoxin levels}

The occurrence of mite species varies between countries, and even in the same country it may vary between regions. $D$. pteronyssinus and $D$. farinae were analysed in the present study. The concentrations of major mite allergen Der $f 1$ in floor and mattress dust were 2.5-3.5 times higher than Der $p 1$ levels. This is similar to findings of other German studies $[18,19]$ in which $D$. farinae was found to be the predominant species. Concentrations of Der $p 1$ and Der $f 1$ in mattress dust were 5- and 6.5-times higher than in living room floor dust. Der $p 1$ and $\operatorname{Der} f 1$ levels in mattress dust were higher than in floor dust from bedrooms and living rooms. This is in accordance with the results of other studies [20-22].

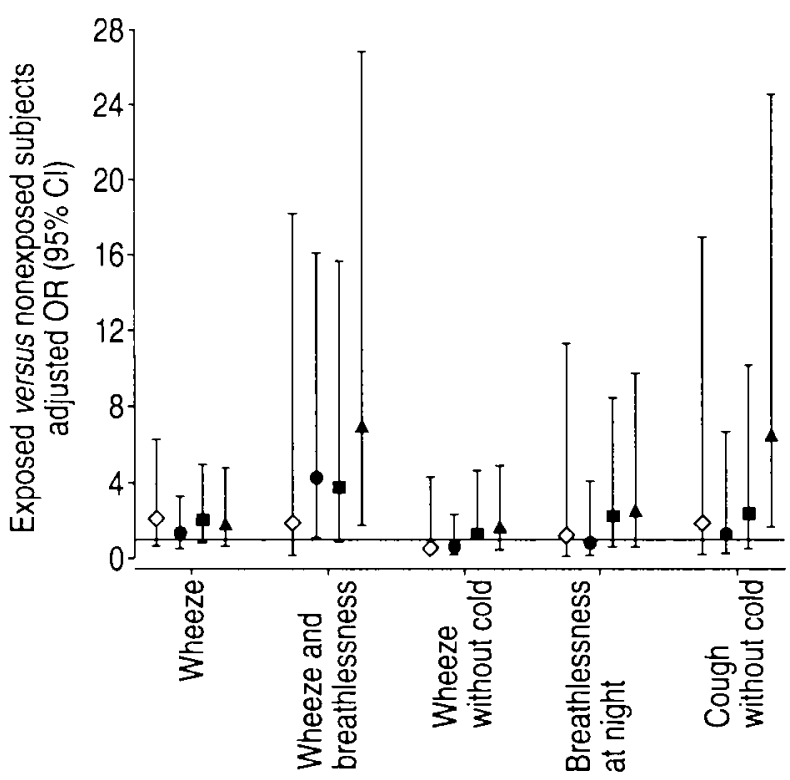

Fig. 1. - Adjusted odds ratios (OR) and 95\% confidence intervals (CI) for selected respiratory symptoms comparing low exposure to mite and cat allergens to high exposure to one single allergen and mixtures of several allergens. $\diamond:$ Dermatophagoides pteronyssinus antigen 1 (Der $p$ 1) $>10 \mu \mathrm{g} \cdot \mathrm{g}^{-1}$ (total number of subjects $(\mathrm{N})=32$ ); -: D. farinae antigen 1 (Der $f 1)>10 \mu \mathrm{g} \cdot \mathrm{g}^{-1} \quad(\mathrm{~N}=55)$; $\mathbf{~}$ : cat antigen $\mathrm{d} 1$ (Fel d 1$)>8 \mu \mathrm{g} \cdot \mathrm{g}^{-1}(\mathrm{~N}=49)$; $\mathbf{\Lambda}:$ Der $p 1>10 \mu \mathrm{g} \cdot \mathrm{g}^{-1}$ and/or Der $f 1>10 \mu \mathrm{g} \cdot \mathrm{g}^{-1}$ and/or Fel $d 1>8 \mu \mathrm{g} \cdot \mathrm{g}^{-1} \quad(\mathrm{~N}=34)$. The horizontal line represents the null hypothesis that the respective $\mathrm{OR}=1$. 


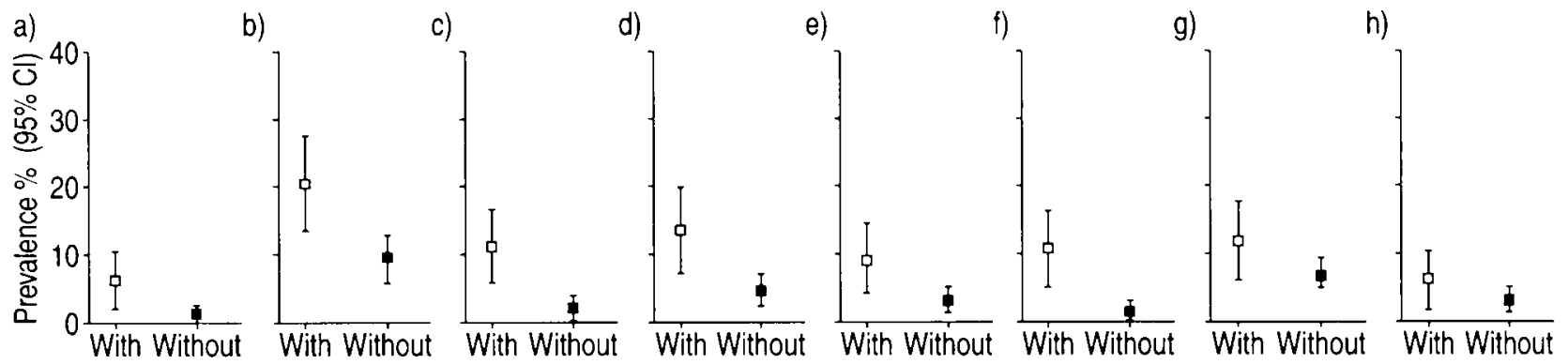

Fig. 2. - Prevalence and 95\% confidence intervals (CI) of a) asthma attacks, b) wheeze, c) wheeze and breathlessness, d) wheeze without cold, e) shortness of breath at rest, f) breathlessness at night, g) cough at night, and h) cough without cold in winter, for subjects with $(\square)$ and without (ם) allergic sensitization. Allergic sensitization refers to $\geqslant 1$ serum specific immunoglobulin-E (IgE) $\geqslant 0.70 \mathrm{kU} \cdot \mathrm{L}^{-1}$ against Alternaria alternata (m6), Aspergillus fumigatus (m3), tree pollen (tx5), birch (t3), Cladosporium herbarum (m2), Dermatophagoides pteronyssinus (d1), D. farinae (d2), grass pollen (gx1, gx4), Phleum pratense (g6), dog dander (e5), cat dander (e1), weed pollen (wx3), and Blatella germanica (i6).

Although only $15.6 \%$ of the subjects had a cat during the past 12 months, the major cat allergen $\mathrm{Fel} d 1$ was found in $97.5 \%$ of the homes. This supports the fact that cat allergen is ubiquitous due to passive transport [23]. Bollinger et al. [24] found Fel $d 1$ levels capable of causing upper and lower respiratory symptoms in settled dust of homes without cats. Therefore, they concluded that the assessment of cat exposure should not be based solely on the presence or absence of a cat in the home. Fel $d 1$ levels $>8 \mu \mathrm{g} \cdot \mathrm{g}^{-1}$ were found in $11 \%$ of the homes where no cat was kept. Cat allergen content was lower in bedroom floor dust than in living room floor dust. This was also reported by Custovic et al. [25]. Endotoxin concentrations in living room floor dust were in line with the concentrations reported by Michel et al. [26].

\section{Mite allergens and respiratory health}

Since allergen exposure plays a major role in the pathogenesis of asthma and allergic sensitization in early childhood, or even prenatally, most studies include children. There are only a few studies on adults analysing the impact of allergen exposure on asthma and allergies. CHAN-YEUNG et al. [27] did not find a relationship between total allergen levels (sum of Der $p 1$ and Der $f 1$ ) and severity of asthma in adults either with or without house dust mite allergy, whereas Custovic et al. [28], as well as TunNiCLIFFE et al. [29], demonstrated a relationship between severity of asthma and exposure to Der $p 1$ in asthmatics sensitized to house dust mite. In the present study, the risk of asthma attacks and respiratory symptoms was not found to be increased continuously with exposure to mite allergens. For this reason, allergen levels were not used as continuous variables in the regression analysis, but were classified into two categories. The levels of $2 \mu \mathrm{g}$ (data not shown) and $10 \mu \mathrm{g}$ group I dust mite allergen, which have been proposed to increase the risk of acute attacks of asthma and symptoms, were used as cut-off values. Stronger effects (except for cough without cold in winter) were found using $10 \mu \mathrm{g}$ as the cut-off value. Exposure to $>10 \mu \mathrm{g}$ mite allergen (Der $p 1$ plus $\operatorname{Der} f 1$ ) and in particular, exposure to $>10 \mu \mathrm{g}$ Der $f 1$ per gram of dust, was found to be a risk factor for respiratory symptoms. Although Der $p 1$ and Der $f 1$ are highly crossreactive, the effect estimates for the sum of Der $p 1$ and Der $f 1$ were weaker than the presented effects of $\operatorname{Der} f 1$. No effect was found for $\operatorname{Der} p 1$ alone, although the two antigens seem to be biologically rather similar. One possible explanation for this might be that $\operatorname{Der} f 1$ is the predominant species in the region under study and that $\operatorname{Der} f 1$ levels are much higher than $\operatorname{Der} p 1$ levels. A relationship between presence of house dust mites and asthma-related respiratory symptoms in adults has also been demonstrated by BJÖRNSSON et al. [30]. In this Swedish study, the presence of house dust mites was assessed by applying the semiquantitative ACAREX test. Since this test is not species specific, it was not possible to clarify the role of different species of mites. Alvarez et al. [31] found asthma symptoms to be at least partially dependent on current exposure to $\operatorname{Der} p 1$.

\section{Cat allergens and respiratory health}

Roost et al. [32] found positive associations between the community prevalence of cat and the community prevalence of respiratory symptoms, physician-diagnosed asthma, and current asthma medication thus demonstrating the importance of cat allergens with respect to asthma and respiratory symptoms. Fel $d 1$ concentrations $>8 \mu \mathrm{g} \cdot \mathrm{g}^{-1}$ were found to be a risk factor for cough at night. The risk of respiratory symptoms was strongly increased when subjects were sensitized in addition to high exposure. The authors conclude that exposure to $\mathrm{Fel} d 1$ levels $>8 \mu \mathrm{g} \cdot \mathrm{g}$ dust $^{-1}$ is a risk factor for asthma attacks and respiratory symptoms in sensitized subjects. These findings are in line with the findings of NoERTJojo et al. [33], who found cat owners to have a significantly higher risk of having current asthma and asthma-like symptoms compared to persons without cats. In the subset with positive skin-prick tests, they found that those who were allergic to cat dander had a significantly higher risk of current asthma than those not allergic to cat dander and not keeping a cat. Because of sample size limitations, it was not possible to do stratified analyses on cat-sensitized subjects in 


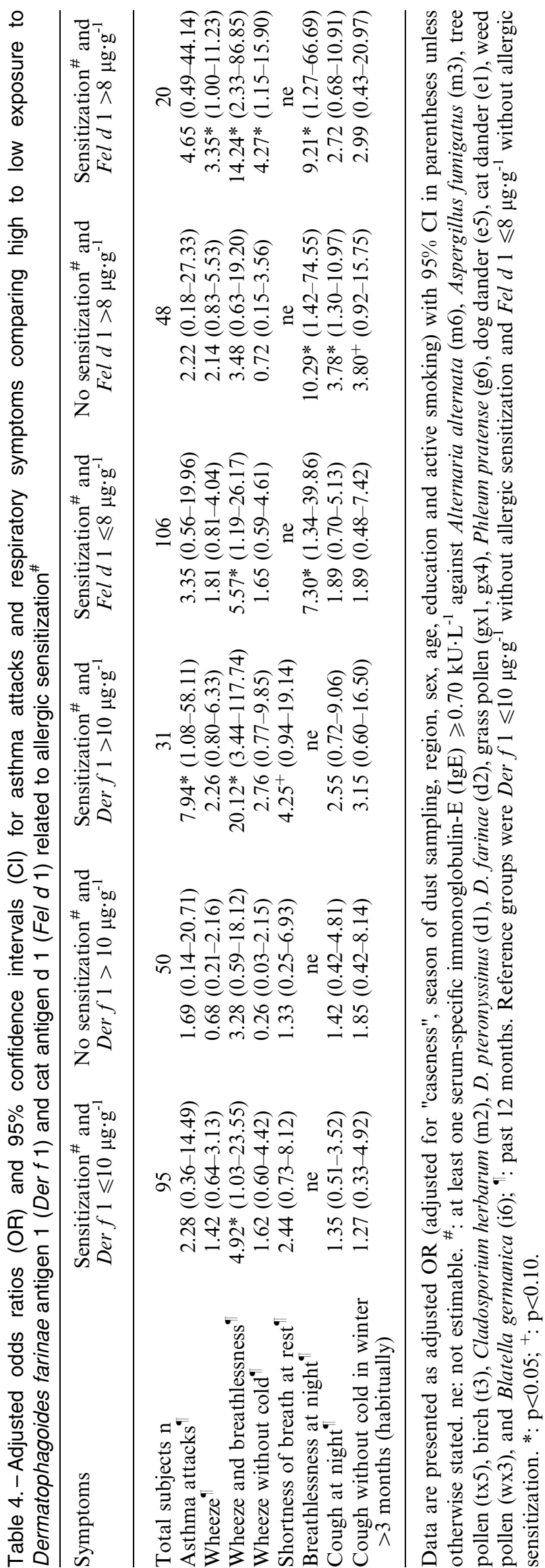

this study. In contrast, CHAN-YEUNG et al. [27] did not find a relationship between Fel $d 1$ and severity of asthma, either in adults with or without allergy to cats. Not only sensitized, but also nonsensitized subjects were found to have an increased risk of nocturnal breathlessness, nocturnal cough, and cough without cold in winter when exposed to $>8 \mu \mathrm{g} \mathrm{Fel} d 1$ per gram of dust. The reason for this is not yet clear. Active smoking was regarded as one possible factor explaining this dose-dependent effect in nonsensitized subjects, but smoking was not found to be associated with respiratory health, neither by itself nor as a cofactor in combination with a high allergen load.

\section{Endotoxins and respiratory health}

Michel et al. [26] found that the concentration of endotoxin measured in house dust is an important determinant of asthma severity in house dust mitesensitized subjects. In the present study, endotoxins were not measured in mattress dust, but only in living room floor dust. Endotoxins in mattress dust were not found to affect respiratory health, neither by themselves nor as cofactors with high allergen levels (data not shown). One possible explanation for this lack of association might be that exposure to endotoxins, like exposure to allergens, is of major importance while sleeping, since people come into very close contact with it in their beds. A tendency towards higher frequencies of asthma attacks and respiratory symptoms was found among subjects exposed to elevated concentrations of endotoxins. Weak, but statistically significant, positive correlations were found between mite and cat allergens in mattress dust on the one hand and endotoxin concentrations in living room floor dust on the other. It is assumed that correlations would be stronger if both allergens and endotoxins were measured in mattress dust and that the correlation between allergens and endotoxins may explain the increase in risk of symptoms, even in nonsensitized subjects.

\section{Mixtures of mite and cat allergens and respiratory health}

Studies on the impact of exposure allergens in house dust on asthma-like symptoms focused either on mite or on cat allergen. Simultaneous exposure to elevated levels of more than one allergen was not reported in literature. In the present study, subjects exposed to elevated concentrations of at least two of the regarded allergens were found to have up to a seven-fold increase in the risk of respiratory symptoms in comparison with nonexposed subjects.

\section{Conclusions}

Indoor exposure to mite allergen (Dermatophagoides farinae antigen 1) and cat allergen (cat antigen 1) is a risk factor for asthma attacks and respiratory symptoms in adults, but not exposure to 
Dermatophagoides pteronyssinus antigen 1. Subjects exposed to elevated levels of two or more of the aforementioned allergens had an increased risk of respiratory symptoms, compared to subjects exposed to elevated levels of a single allergen. Sensitized subjects were found to have an increased risk of asthma attacks and respiratory symptoms, which was strengthened if they were additionally exposed to elevated concentrations of Dermatophagoides farinae antigen 1 or cat antigen 1 .

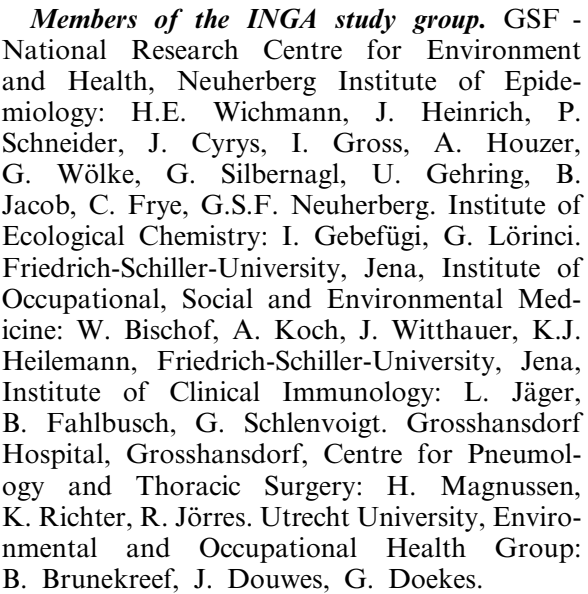

\section{References}

1. Platts-Mills TA, Carter MC. Asthma and indoor exposure to allergens. $N$ Engl J Med 1997; 336: 13821384.

2. Gross I, Heinrich J, Fahlbusch B, Jager L, Bischof W, Wichmann HE. Indoor determinants of Der $p 1$ and $\operatorname{Der} f 1$ concentrations in house dust are different. Clin Exp Allergy 2000; 30: 376-382.

3. Lang JD, Mulla MS. Distribution and abundance of house dust mites, Dermatophagoides spp., in different climatic zones of Southern California. Environ Entomol 1977; 6: 213-216.

4. Rosenstreich DL, Eggleston P, Kattan M, et al. The role of cockroach allergy and exposure to cockroach allergen in causing morbidity among inner-city children with asthma. N Engl J Med 1997; 336: 13561363.

5. Goldstein IF, Reed CE, Swanson MC, Jacobson JS. Aeroallergens in New York inner-city apartments of asthmatics. EXS 1987; 51: 133-138.

6. Fahlbusch B, Heinrich J, Gross I, Jager L, Richter K, Wichmann HE. Allergens in house-dust samples in Germany: results of an East-West German comparison. Allergy 1999; 54: 1215-1222.

7. Wahn U, Lau S, Bergmann R, et al. Indoor allergen exposure is a risk factor for sensitization during the first three years of life. J Allergy Clin Immunol 1997; 99: 763-769.

8. Kuehr J, Frischer T, Meinert R, et al. Mite allergen exposure is a risk for the incidence of specific sensitization. J Allergy Clin Immunol 1994; 94: 44-52.

9. Munir AK, Kjellman NI, Bjorksten B. Exposure to indoor allergens in early infancy and sensitization. J Allergy Clin Immunol 1997; 100: 177-181.
10. Nowak D, Heinrich J, Jorres R, et al. Prevalence of respiratory symptoms, bronchial hyperresponsiveness and atopy among adults: West and East Germany. Eur Respir J 1996; 9: 2541-2552.

11. Heinrich J, Richter K, Magnussen H, Wichmann HE. Is the prevalence of atopic diseases in East and West Germany already converging? Eur J Epidemiol 1998; 14: 239-245.

12. Burney PG, Luczynska C, Chinn S, Jarvis D. The European Community Respiratory Health Survey. Eur Respir J 1994; 7: 954-960.

13. Richter K, Heinrich J, Jorres RA, Magnussen H, Wichmann HE. Trends in bronchial hyperresponsiveness, respiratory symptoms and lung function among adults: West and East Germany. Respir Med 2000; 94 : 668-677.

14. Platts-Mills TA, Thomas WR, Aalberse RC, Vervloet D, Chapman MD. Dust mite allergens and asthma: report of the second international workshop. J Allergy Clin Immunol 1992; 89: 1046-1060.

15. Bischof W, Koch A, Gehring U, Fahlbusch B, Heinrich J, Wichmann HE. Predictors of high endotoxin concentrations in German homes. Proc Healthy Buildings 2000; 1: 251-256.

16. Platts-Mills T, de Weck AL. Dust mite allergens and asthma - A worldwide problem. J Allergy Clin Immunol 1988; 83: 416-427.

17. Gelber LE, Seltzer LH, Bouzoukis JK, Pollart SM, Chapman MD, Platts-Mills TA. Sensitization and exposure to indoor allergens as risk factors for asthma among patients presenting to hospital. Am Rev Respir Dis 1993; 147: 573-578.

18. Kuehr J, Frischer T, Karmaus W, et al. Natural variation in mite antigen density in house dust and relationship to residential factors. Clin Exp Allergy 1994; 24: 229-237.

19. Wahn U, Lau-Schadendorf S, Ehnert B, Weber A. House dust mites in German homes. In: Ring $\mathrm{J}$, Przybilla B, eds. New Trends in Allergy III. Berlin, Springer Verlag, 1991; pp. 447-453.

20. Hirsch T, Range U, Walther KU, et al. Prevalence and determinants of house dust mite allergen in East German homes. Clin Exp Allergy 1998; 28: 956-964.

21. Hirsch T, Kuhlisch E, Soldan W, Leupold W. Variability of house dust mite allergen exposure in dwellings. Environ Health Perspect 1998; 106: 659-664.

22. Verhoeff AP, Van Strien RT, Van Wijnen JH, Brunekreef B. House dust mite allergen (Der p I) and respiratory symptoms in children: a case-control study. Clin Exp Allergy 1994; 24: 1061-1069.

23. Ledford DK. Indoor allergens. J Allergy Clin Immunol 1994; 94: 327-334.

24. Bollinger ME, Eggleston PA, Flanagan E, Wood RA. Cat antigen in homes with and without cats may induce allergic symptoms. J Allergy Clin Immunol 1996; 97: 907-914.

25. Custovic A, Simpson A, Pahdi H, Green RM, Chapman MD, Woodcock A. Distribution, aerodynamic characteristics, and removal of the major cat allergen Fel d 1 in British homes. Thorax 1998; 53: 33-38.

26. Michel O, Kips J, Duchateau J, et al. Severity of asthma is related to endotoxin in house dust. Am J Respir Crit Care Med 1996; 154: 1641-1464.

27. Chan-Yeung M, Manfreda J, Dimich-Ward H, et al. Mite and cat allergen levels in homes and severity of 
asthma. Am J Respir Crit Care Med 1995; 152: 18051811.

28. Custovic A, Taggart SC, Francis HC, Chapman MD, Woodcock A. Exposure to house dust mite allergens and the clinical activity of asthma. J Allergy Clin Immunol 1996; 98: 64-72.

29. Tunnicliffe WS, Fletcher TJ, Hammond $\mathrm{K}$, et al. Sensitivity and exposure to indoor allergens in adults with differing asthma severity. Eur Respir J 1999; 13: 654-659.

30. Björnsson E, Norbäck D, Janson C, et al. Asthmatic symptoms and indoor levels of micro-organisms and house dust mites. Clin Exp Allergy 1995; 25: 423-431.
31. Alvarez MJ, Olaguibel JM, Acero S, Garcia BE, Tabar AI, Urbiola E. Effect of current exposure to Der $p 1$ on asthma symptoms, airway inflammation, and bronchial hyperresponsiveness in mite-allergic asthmatics. Allergy 2000; 55: 185-190.

32. Roost HP, Kunzli N, Schindler C, et al. Role of current and childhood exposure to cat and atopic sensitization. European Community Respiratory Health Survey. J Allergy Clin Immunol 1999; 104: 941-947.

33. Noertjojo K, Dimich-Ward H, Obata H, Manfreda J, Chan-Yeung M. Exposure and sensitization to cat dander: asthma and asthma-like symptoms among adults. J Allergy Clin Immunol 1999; 103: 60-65. 